\title{
Are the North Atlantic and Arctic Oscillations Reflected in Scandinavian Glacier Mass Balance Records?
}

Analysis of time series of temperature and precipitation records reveal moreor-less regular fluctuations on top of more stochastic variations. The climate system may also undergo longer term decadal to millennial scale perturbations. Regular, short term (decadal to century scale) climate variations may be caused by short-term external and/or internal forcing mechanisms. The equatorial Pacific El Niño and Southern Oscillation (ENSO), the thermohaline circulation (THC), the North Atlantic Oscillation (NAO) and the Arctic Oscillation (AO) are the most well established interannual to decadal coupled ocean-atmospheric oscillations.

When discussing possible future climatic changes due to increased atmospheric concentration of greenhouse gases, it is important to understand the natural climatic variability of the past. The North Atlantic Ocean and the adjacent continental areas in NW Europe are of key importance for climate reconstruction both on short and long time scales. The North Atlantic Oscillation (NAO) and the Arctic Oscillation (AO) are the major modes of climate variability in the Northern Hemisphere. In NW Europe, interannual atmospheric climate variability during the last decades has mainly been attributed to the NAO, causing variations in the winter weather in North America, over the NE North Atlantic and the adjacent continents. The atmospheric circulation during the winter season, the season which exhibits the strongest interdecadal variability, commonly displays a strong meridional (north-south) pressure contrast, with low air pressure centred close to Iceland and high air pressure near the Azores. The weather in the North Atlantic region, in particular in winter, is commonly characterised by strong eastward air-flow between the 'Icelandic low' and the 'Azores high' and by a stormtrack which moves eastward towards NW Europe. The NAO index is based on the difference of normalised sea-level air pressures between the Azores and Iceland. The positive polarity of the $\mathrm{AO}$ is characterised by a strengthening of the polar vortex from the surface to the lower stratosphere. Under these conditions, cool winds blow across eastern Canada while storms in the North Atlantic bring precipitation and mild air to NW Europe. During negative polarity of the AO, on the other hand, cool air flows to the Midwestern United States and western Europe while storms bring

\begin{tabular}{|lcccccccc|}
\hline \multirow{2}{*}{ GLACIER } & \multicolumn{2}{c}{$\mathbf{B}_{\mathbf{w}} / \mathrm{NAO}$} & \multicolumn{2}{c}{$\mathbf{B}_{\mathrm{N}} / \mathrm{NAO}$} & \multicolumn{2}{c}{$\mathbf{B}_{\mathrm{w}} / \mathbf{A O}$} & \multicolumn{2}{c}{$\mathbf{B}_{\mathrm{N}} / \mathrm{NAO}$} \\
\hline 1. Allfotbreen & $\mathbf{r}$ & $\mathbf{R}^{2}$ & $\mathbf{r}$ & $\mathbf{R}^{2}$ & $\mathbf{r}$ & $\mathbf{R}^{2}$ & $\mathbf{r}$ & $\mathbf{R}^{2}$ \\
\hline 2. Hardangerjøkulen & 0.773 & 0.597 & 0.719 & 0.517 & 0.604 & 0.365 & 0.592 & 0.351 \\
\hline 3. Nigardsbreen & 0.735 & 0.540 & 0.700 & 0.490 & 0.449 & 0.202 & 0.440 & 0.194 \\
\hline 4. Hellstugubreen & 0.700 & 0.491 & 0.585 & 0.342 & 0.420 & 0.176 & 0.392 & 0.154 \\
\hline 5. Storbreen & 0.643 & 0.413 & 0.454 & 0.206 & 0.472 & 0.223 & 0.341 & 0.116 \\
\hline 6. Gråsubreen & 0.620 & 0.385 & 0.500 & 0.250 & 0.487 & 0.237 & 0.401 & 0.161 \\
\hline 7. Storglaciären & 0.589 & 0.347 & 0.319 & 0.102 & 0.352 & 0.124 & 0.089 & 0.008 \\
\hline 8. Engabreen & 0.487 & 0.237 & 0.415 & 0.172 & 0.416 & 0.173 & 0.356 & 0.127 \\
\hline 9. Midtre Lovénbreen & 0.354 & 0.125 & 0.495 & 0.245 & 0.341 & 0.116 & 0.424 & 0.180 \\
\hline 10. Austre Brøggerbreen & 0.089 & 0.008 & 0.000 & 0.000 & 0.335 & 0.112 & 0.000 & 0.000 \\
\hline
\end{tabular}

Table 1. Pearson's correlation coefficient $(r)$ and the coefficient of determination $\left(R^{2}\right)$ between the North Atlantic Oscillation (NAO) (Jones et al., 1997, with later updates) index (December-March) and Arctic Oscillation (AO) index (Thompson and Wallace, 1998, with later updates) and winter (Bw) and summer (Bs) balance on $10 \mathrm{NW}$ European glaciers. Glaciers 1, 2, 3, 4, 5, 6 are located in southern Norway, glacier 8 in northern Norway, 7 in northern Sweden, and 9 and 10 on western Svalbard. Glacier mass-balance data from glaciers on the Norwegian mainland from Kjøllmoen (1998), the two Svalbard glaciers from Jania and Hagen (1996 and later updated by J.O. Hagen pers. comm.) and Storglaciären in northern Sweden from Holmlund et al. (1996).

Figure 1. Upper panel: Correlation $\left(R^{2}\right)$ between winter balance $(B w) / N A O$ and between the net balance $(B n) / N A O$. Lower panel: Correlation (R2) between the Bw/AO and Bn/AO. The numbers in Table 1.

rainfall to the Mediterranean region. Variations in the NAO and AO indices are reflected in the mass balance records of Scandinavian glaciers. A correlation between the NAO (December-March), and AO (January-March) indices and glacier mass balance data from 10 Scandinavian glaciers, shows that the NAO and $\mathrm{AO}$ indices are best correlated with mass balance data from maritime glaciers in western Norway and that the correlation decreases with increasing continentality (Figure 1, Table 1).

\section{References}

Holmlund, P., et al. Geog. Ann., 78A, 105-114, 1996.

Jania, J. \& Hagen, J.O., IASC Report, No. 5, 62 pp, 1996.

Jones, P.D., et al. Internat. J. Climatology, 17, 1433-1450, 1997.

Kiøllmoen, B., Rapport, 20, Norges vassdrags- og energidirektorat. 134 pp, 1998.

Thompson, W.J. \& Wallace, M., Geophys. Res. Lett., 25, 1297-1300, 1998.

\section{Atle Nesje and Svein Olaf Dahl}

Department of Geology, University of Bergen, Norway atle.nesje@geol.vib.no

svein.dahl@geog.uib.no 